\title{
Editorial: Trafficking in Minors: Confronting complex realities, structural inequalities, and agency
}

\author{
Brenda Oude Bremil and Borislav Gerasimov
}

Please cite this article as: B Oude Breuil and B Gerasimov, 'Editorial: Trafficking in Minors: Confronting complex realities, structural inequalities, and agency', Anti-Trafficking Review, issue 16, 2021, pp. 1-9, https://doi.org/10.14197/atr. 201221161

On the tenth anniversary of the Anti-Trafficking Review, and with 2021 proclaimed the International Year for the Elimination of Child Labour, ${ }^{1}$ this Special Issue on 'Trafficking in Minors' is well-timed. You might even say it comes a bit late, considering the topic's central place in the representation of human trafficking, which is in itself an urgent matter that has been widely discussed in previous issues of the journal. If there is one topic in the trafficking discourse that evokes particularly emotional outrage and a passionate, oftentimes moralistic 'call to arms', it is child trafficking. Without becoming cynical about many doubtlessly well-intentioned actions to protect children from being victimised, some critique is needed here. One only has to enter 'child trafficking' into an internet search engine and watch the images generated-big, innocent eyes looking straight into the camera in silent protest; small bodies curled up in helpless, foetal positions; hands protectively held up to block invisible evils; and faces distorted in expressions of agony and fear, with mouths covered by tape with 'Help' written on it, or by adult hands - to understand that stereotypical and symbolic depictions of children are oftentimes (ab)used to raise the stakes. Children are currency in political praxis and public discourses, as they symbolise the continuity of communities, feelings of 'home' and belonging, and that which is most valuable in people's lives. If children are maltreated, it feels as if the communities they belong to are endangered, too.

1 United Nations General Assembly, Resolution adopted by the General Assembly on 25 July 2019, A/RES/73/327; see also 'International Year for the Elimination of Child Labour', retrieved 19 March 2021, https:/ / endchildlabour2021.org.

This is an open-access article distributed under the terms of the Creative Commons Attribution License (CC-BY). Under the CC-BY license, the public is free to share, adapt, and make commercial use of the work. Users must always give proper attribution to the authors and the Anti-Trafficking Review. 
The affective appeal and political currency of the topic of trafficking in minorsand the related issue of child labour-do not do a great service to the empirical study of the phenomenon. With the emotional stakes so high, academic and nonacademic researchers, as well as civil society actors and policymakers, are quickly drawn into (or unwillingly ascribed) polarised positions, perceived as either serving the 'abolitionists' (claiming, tout court, that child trafficking should be eradicated), or being 'liberal relativists' (assumed to relativise child trafficking and child labour as cultural practices that one should try to understand). This polarisation clouds observation and analysis as well as actions evolving from them in many ways, as illustrated by the contributions in this Special Issue.

A first challenge in the study of trafficking in minors is studying it at all. Notwithstanding its central position in (social) media representations of human trafficking and the fact that children account for around one-third of all identified victims globally, ${ }^{2}$ its empirical, academic study leaves much ground to be explored. There is a respectable pile of NGO reports on the phenomenon, but they often lack academic rigour and are just as often part of the 'politics of trafficking' (and what Laura Agustín aptly labelled 'the rescue industry'3). Moreover, research on trafficking for sexual exploitation is, in the broader trafficking study field, overrepresented and overshadows other forms of trafficking in minors, such as trafficking for forced labour or exploitation in criminal activities. In this Special Issue we have thus prioritised articles that are based on empirical studiesover, for example, literature studies or (quantitative) country reviews - and focus on these other, less studied forms of trafficking. Notwithstanding the explicit invitation to empirical researchers in the call for papers, methodologically sound, in-depth, empirical studies on trafficking in minors were in the minority. This need not surprise us. Research on (and with) minors, so caught up in a discourse of vulnerability and protection, is methodologically challenging. The group of victimised minors, as well as that of potential traffickers, is hard to access and researchers often resort to approaching minors through the organisations protecting them-with a biased group of respondents as a result. Moreover, ethical requirements in some countries-sometimes more concerned with protecting the research organisations' names than protecting minors against potential research harms ${ }^{4}$ — make empirical research among (potentially) victimised minors without the mediating interference of child protection organisations next to impossible.

2 UNODC, Global Report on Trafficking in Persons 2020, United Nations, Vienna, 2021.

3 L M Agustín, Sex at the Margins: Migration, Labour Markets and the Rescue Industry, Zed Books, London, 2007.

4 See D Siegel and R de Wildt, Ethical Concerns in Research on Human Trafficking, Springer, London, 2016, in particular part III (Boyd and Bales; Marcus and Curtis; Horning and Paladino) and part I, chapter 6 (Zhang). 
A second challenge in researching trafficking in minors is to critically address socio-economic and political root causes and structural inequalities through this jungle of politicised discourse, stereotypical imaginations, sweeping numbers, unverified claims, and 'quick-fix', repressive solutions. Inequalities hamper the research on two (and possibly more) levels. On the one hand, macro-level, geopolitical inequalities are not only at the basis of the phenomenon-with the demand for trafficked minors going, typically, 'from the West to the Rest' and the supply vice versa-but also hinder in-depth understanding of it. With the 'Global North' still dictating the research agenda, the theoretical framework, and the normative starting points and means to address it, local understandings of the processes behind trafficking in minors are often ignored. As we can see in the contributions of, for example, Koomson and Abdulai, Dottridge, and Okyere, Agyeman and Saboro in this Special Issue, this carries the risk of producing superficial understandings of the phenomenon that create harm, rather than improving victimised minors' (and their parents' or guardians') living conditions.

On the other hand, micro-level inequalities hamper research as well, with minors generally finding themselves in a subordinate position vis-à-vis adults. The own, insiders' accounts of trafficked minors are often missing in academic studies due to the aforementioned methodological and ethical challenges of involving them in such studies. Trafficked minors are legally defined as incapable of making informed decisions at all, and policies aimed at addressing their living conditions and the protection they should receive are mostly failing to take their expert knowledge into account. Anti-trafficking policies may, furthermore, reflect and exacerbate existing gender inequalities, as Durisin and van der Meulen and Oude Breuil discuss in this issue. We were able to address the lack of minors' voices in trafficking studies and policies only to a limited extent, with their perspectives being voiced in the contributions of Koomson and Abdulai, and of Soltis and Taylor Diaz. The lack of academic articles departing from minors' own perspectives may, we hope, be taken as an invitation or, rather, an urgent call, for future researchers to take up this challenge and inventively apply qualitative, participatory, visual, and virtual methods to study trafficking in minors through the minors' own eyes.

A third challenge in the study of and approach to trafficking in minors is to address new developments in this field, as well as existing aspects of the phenomenon that take a different meaning in contemporary conditions. To pick just a few random recent examples: the (sensationally mediatised) concerns about 'missing children' in the so-called 'refugee crisis' in Europe, and accompanying suggestions that they have become victims of child trafficking, ${ }^{5}$ the prevalent use of social media

5 See, for instance, No author, 'Migrant Crisis: More than 10,000 children "missing", $B B C$, 31 January 2016, retrieved 25 March 2021, https:/ /www.bbc.com/news/worldeurope-35453589. 
by minors all over the world and the potential new risks of exploitation this may evoke (as well as the climate of moral panic among adults about youths' internet behaviour); ${ }^{6}$ or the recently experienced difficulties of prospective parents to pick up their newborns of surrogate mothers in foreign countries without being charged with 'child trafficking' - as well as further dramatic developments in this field due to closed borders in pandemic times. ${ }^{7}$ Such developments need our attention: be it to distinguish 'real' issues from media-induced moral panics, and 'trafficking in minors' from other, related but distinct phenomena, or to gain in-depth understanding of the exploitative processes at work. In this Special Issue we have therefore included an insightful contribution by Hyder-Rahman on conceptual complexities of the label 'child trafficking' in the phenomenon of reproductive tourism, and a short article by Gill focusing on Philippine youths' involvement in producing online sexual content in order to contribute to their own or their families' income.

A fourth and final challenge concerns not so much our knowledge on trafficking in minors, but our response to it. From existing studies on approaching trafficked minors, we can distil seven principles that should be adhered to in order for an intervention to be successful: the intervention should start from a human rights (rather than a criminal law) perspective, it should be child-focused, culturally sensitive, aimed at addressing root causes, based on sufficient knowledge of the phenomenon among all involved parties, integral (that is, involving collaboration of different institutions in the field of child protection as well as law enforcement, adhering to the aforementioned principles), and transnationally oriented. ${ }^{8}$

Undoubtedly, adhering to all these principles is a complex undertaking. The contributions in this Special Issue elaborate on some of the challenges. Several contributions confirm the need to step away from merely criminal law-focused interventions, and emphasise the need to address structural root causes linked to the migration and work of minors (for example those by Dottridge or Okyere, Agyeman, and Saboro). They also show that the criminal law perspective and

6 See, for instance, L Lamberink, "Internet Child Exploitation Sees "Drastic Increase" in Yukon: RCMP', MSN, 24 March 2021, https:/ /www.msn.com/en-ca/news/canada/ internet-child-exploitation-sees-drastic-increase-in-yukon-rcmp/ar-BB1eUM6w.

7 See, for instance, A Wipatayotin, 'Surrogate Babies Stranded by Covid', Bangkok Post, 30 January 2021, https://www.bangkokpost.com/thailand/general/2059463/ surrogate-babies-stranded-by-covid.

8 These seven principles are retrieved from a systematic literature study conducted by the author, in A Bos, K Loyens, V Nagy and B Oude Breuil, Uitbuiting van Minderjarigen in de Criminaliteit in Nederland, Utrecht University, Utrecht, 2016. The weak point here is that these studies generally pinpoint what should work, based on literature and on 'bad examples' from practice, but it has not (always) been substantiated by evidence on what does work. 
approach may be counterproductive, especially in cases where what is termed 'trafficking' but is, in fact, children's work away from home, is part of family subsistence strategies. Other contributions (such as those by Krsmanovic and Oude Breuil) show the differences in governments' treatment of their own citizens versus migrants and point out that existing intervention strategies often take as a starting point the living conditions of white citizens and, thus, do not work out well for minors belonging to mobile, racialised or ethnic minority groups. This results in social assistance interventions for the former and criminal law interventions for the latter, furthering criminalisation and stigmatisation of migrant and/or non-white families. Similarly, the contribution of Soltis and Taylor Diaz highlights the inhumane treatment of migrant children by immigration authorities even when their exploitation has been recognised.

We hope that the articles featured here will provide new evidence and food for thought about trafficking in minors and the responses to it. As the International Year for the Elimination of Child Labour progresses, we also hope they will contribute to the existing calls to better understand what exactly needs to be eliminated and how. ${ }^{9}$

\section{This Special Issue}

The issue opens with an article by Mike Dottridge who reviews the development of policies and interventions against child trafficking in three countries-Benin, Vietnam, and the United Kingdom. Based on his decades of experience in the anti-trafficking field, Dottridge argues that these (and many other) countries fail to adequately distinguish between the crime of child trafficking and adolescents' independent migration for work. He suggests that this is, at least in part, because there is no internationally accepted understanding about the age at which children habitually start engaging in work, including away from home. This leads to authorities in different countries applying very general assumptions-for example, that all vidomègon in Benin or all undocumented Vietnamese children working illegally in the UK have been trafficked. He concludes that states should recognise that for some children it may be beneficial to migrate and start earning before they turn 18, and prioritise economic and social measures in order to address patterns of migration and exploitation.

9 No author, 'Open Letter: Change course on the International Year for the Elimination of Child Labour', OpenDemocracy, 27 January 2021, https:/ /www.opendemocracy.net/ en/beyond-trafficking-and-slavery/open-letter-change-course-international-yearelimination-child-labour. 
The next article, by Bernard Koomson and Dawuda Abdulai, also examines the importance of local understandings of childhood, but in the context of fishing communities on Lake Volta in Ghana. Based on empirical research among working children, their parents, and key informants, they demonstrate that the community's conceptualisation of a child is most commonly as someone below the age of 13. Consequently, the participation of children above 13 in fishing, including while away from home, is seen by the community as work socialisation and a way to assist the children's families — not as crime, as prescribed by Ghana's Human Trafficking Act. The authors call for the consideration of a social age category within existing child rights and human trafficking laws in Ghana: this would help shift the focus of anti-trafficking interventions away from an abolitionist agenda and towards a protectionist one that reduces the risk of harm for children rather than removing them completely from specific economic activities, as has been the normal practice.

The community's perceptions of abolitionist interventions are highlighted in the next article, by Sam Okyere, Nana K Agyeman and Emmanuel Saboro. The authors analyse campaigns against child trafficking in Ghana and, more specifically, those utilising videos recorded during anti-child trafficking raids on Lake Volta. Their analysis is based on data from eighteen interviews with families of children who were taken during raids, as well as with other community members. The authors describe the shock and grief experienced by the children's families who felt that their children were 'stolen' from them by the NGOs and police who conducted the raids. The community also thought they were grossly misrepresented and stigmatised in NGO campaigns depicting them as forcing their children into trafficking and 'slavery'. Okyere, Agyeman, and Saboro argue that this is part of a broader trend in campaigns against human trafficking and child trafficking of using unsettling images and videos of poverty and abjection to raise funds. Despite some recent progress and recognition in the field that such representations can be extremely problematic, they argue that there is little incentive for NGOs to change their ways because these representations continue to capture the attention of audiences_-and the dollars of donors.

Continuing the theme of representations of child trafficking, the article by Elena Krsmanovic discusses how media in the United Kingdom portray the sexual exploitation of British children differently from that of non-British trafficked minors. Based on an analysis of 151 media articles, Krsmanovic argues that the former regurgitate the 'white slavery' myth and stigmatise particular ethic communities in the country, while the latter problematise primarily the presence of foreign criminals and foreign minors in the country. Furthermore, while the articles about British minors emphasise the need for stronger child welfare and victim support services, reports about trafficked foreign minors only promote harsher policing and prosecution of traffickers as the solution. This differential treatment of the problem, the author suggests, presents a distorted picture and hinders the development of effective strategies to combat it. 
The presentation of child trafficking as a problem typical of certain ethnic communities is also evident in the article by Brenda Oude Breuil. She examines the less well-known form of child trafficking for exploitation in criminal activities in the Netherlands and finds that such cases are conceptualised by frontline actors as a 'Roma problem', leading to blind spots in the identification of trafficking cases among other ethnicities. Itinerant groups, more often than not collectively labelled as 'Roma', are further criminalised in the process. Another perception bias was found in the acknowledgement of girls and boys as victims to this crime: frontline actors were more inclined to grant victim status to girls, seeing boys as guilty 'little rascals' who should be punished. Oude Breuil concludes with a call to identify cases of trafficking of minors for exploitation in criminal activities through a focus on the characteristics of the phenomenon, rather than of the victims, to prevent further stigmatisation, and to consider whether a criminal justice approach is in the best interest of the child in cases where minors' criminal activities directly benefit family survival strategies.

The next article, by Katherine Soltis and Madeline Taylor Diaz, also focuses on child trafficking for exploitation in criminal activities but in the context of the United States. Based on their experience of working in a non-profit organisation that provides legal assistance to migrants and victims of trafficking, the authors highlight the failure of the US immigration system to protect Central American minors exploited for criminal activities by gangs. They provide an overview of the hurdles their clients have to go through to obtain immigration relief, which had only become more cumbersome under the Trump administration. This is part of the broader trend, in the US and elsewhere, towards 'crimmigration' and in contravention to the US government's obligations under the UN Refugee Convention and the domestic Trafficking Victims Protection Act. The authors recommend the incorporation of principles regarding the capacity of minors and the culpability of trafficking victims into the immigration system, in order to ensure that trafficked minors receive the protection they are entitled to.

While these six articles revolve primarily around the issue of child trafficking in the context of migration and work, the final thematic article addresses a different, but equally important and controversial issue. Nishat HyderRahman disentangles the sometimes overlapping but nonetheless distinct issues of commercial gestational surrogacy (CGS) and child trafficking. Through meticulous analysis of international law, she explores the intersections between CGS, the sale of children, and child trafficking vis-à-vis the child and demonstrates that anti-trafficking legislation is not an appropriate response to CGS or 'reproductive tourism', despite the attempts of several countries to conflate the two. She emphasises that CGS is about building families, while child trafficking is about exploiting a child, and labelling CGS as 'child trafficking' unnecessarily punishes all parties - the child, the intended parents, and the surrogate. She concludes that CGS requires carefully crafted laws that attend to the particular 
vulnerabilities of each party and prevent exploitative practices - measures that go beyond the remit of human trafficking laws.

As outlined above, we prioritised the inclusion of conceptual and empirical articles on child trafficking in the context of migration and labour, as well as lesser-known forms (such as exploitation in criminal activities) and emerging issues (such as reproductive tourism) over child trafficking for sexual exploitation. However, we decided to accept two short articles, both of which deal in some way with children in the sex industry, to address this gap, but also because of the important and original perspectives they take.

In the first short article, Elya $\mathbf{M}$ Durisin and Emily van der Meulen discuss how recent concerns about human trafficking in Canada have shifted from a preoccupation with Eastern European women towards the sexual exploitation of Canadian girls and young women. Through a brief review of statements made during the parliamentary debates on the Anti-Human Trafficking Act, 2017, they show how policymakers' declared concerns about the sexual exploitation of 'young girls' become superimposed on adult women. The authors argue that this infantilises women and legitimises the criminalisation of consensual adult sex work, which has been shown to negatively affect sex workers.

In the other short article, Melinda Gill focuses on the problem of online child sexual exploitation (OCSE) in the Philippines. This issue is typically seen as situations where children are forced to create sexual content online by family members or other adults, and the state has responded with awareness-raising campaigns and spectacular raids. However, more recent evidence shows that in many cases children engage in such activities on their own or with the help of peers, making these government responses miss the point. Like Dottridge, and Koomson and Abdulai, Gill's article evokes further reflection on the delicate interplay between the agency of minors and their exploitation (and eventual harm). On the policy level, Gill proposes to address OCSE through long-term interventions, which reduce poverty, improve educational and employment opportunities, and strengthen access to sexual and reproductive health education for both girls and boys, as well as their families.

\section{Conclusion}

One common thread in the contributions in this Special Issue is that the legal definition of trafficking in minors-and, by extension, the approaches to victimised minors that follow from this legal categorisation-is oftentimes a blackand-white simplification of complex realities. There is a plethora of exploitative situations children can find themselves in, and they exhibit different degrees of agency in those situations, depending on social, economic, political, cultural, and individual conditions in their lives. If the contributions in this Special Issue can 
teach us one thing, it is that we need to consider these contextual factors carefully to be able to understand, in-depth, the suffering of individual minors from the exploitation they encounter in their lives, and how they deal with it, as well as how to best address it. The 'fight' against trafficking in minors (and, relatedly, child labour) must not be seen in isolation from larger socio-economic and political issues related to development, access to education, healthcare, decent work and social protections, or discrimination based on race, gender, ethnicity, class, caste, etc. Thus, we have to critically observe and continue to question whether proposed legislation, policies, or interventions truly address these root causes and have the best interest of minors at heart or, rather, aim primarily at protecting rich nations and their citizens from the insecurities these minors confront them with.

Brenda Oude Breuil is senior lecturer at the Willem Pompe Institute for Criminal Law and Criminology, Utrecht University, and researcher in the Utrecht Centre for European Research into Family Law. Her research focuses on human trafficking, exploitation of minors, and other forms of exploitation in the global economy. As an anthropologist and cultural criminologist, she tries to understand the meaning of crime within its socioeconomic, political, and cultural context. She investigated the exploitation of minors in criminal activities for the Dutch government in 2016 and, most recently, co-edited Notes from Isolation: Global criminological perspectives on coronavirus pandemic (Eleven International Publishing, 2021).Email: b.oudebreuil@uu.nl

Borislav Gerasimov is the Communications and Advocacy Coordinator at the Global Alliance Against Traffic in Women and the Editor of the AntiTrafficking Review. He holds a degree in English Philology from Sofia University St Kliment Ohridski, Bulgaria, and has previously worked at women's rights and anti-trafficking organisations in Bulgaria and the Netherlands. He has also been involved in various capacities in the work of organisations supporting Roma youth, LGBTI people, people living with HIV/AIDS, and sex workers. Email: borislav@gaatw.org 